\title{
Permanent neonatal diabetes mellitus - a case report of a rare cause of diabetes mellitus in East Africa.
}

\author{
Catherine Nyangabyaki-Twesigye ${ }^{1}$, Michael Rugambwa Muhame ${ }^{2}$, Silver Bahendeka ${ }^{3}$
}

1. Department of Paediatrics, St. Francis Nsambya Hospital, P.O. Box 7146, Kampala, Uganda,

2. Department of Paediatrics, International Hospital Kampala, P. O. Box 8177, Kampala, Uganda/

Division of Paediatric Critical Care and Children's Heart Disease, School of Child and Adolescent

Health, University of Cape Town, Rm 520, ICH Building, Red Cross War Memorial Children's Hospital,

Klipfontein Road, Rondebosch, 7700, Cape Town, South Africa,

3. Department of Internal Medicine, St Francis Nsambya Hospital, P. O. Box 7146, Kampala, Uganda

DOI: http://dx.doi.org/10.4314/ahs.v15i4.37

Cite as: Nyangabyaki-Twesigye C, Mubame MR, Babendeka S. Permanent neonatal diabetes mellitus - a case report of a rare cause of diabetes mellitus in East Africa. Afri Health Sci. 2015;15(4):1339-41. http:// dx.doi.org/10.4314/abs.v15i4.37

\begin{abstract}
Diabetes mellitus is a metabolic disease characterised by chronically high glucose levels. Genetic factors have been implicated in the aetiology following mutations in a single gene. An extremely rare form of diabetes mellitus is monogenic diabetes, a subset of which is permanent neonatal diabetes, and is usually suspected if a child is diagnosed with diabetes at less than 6 months of age.

We present the first case reported from East Africa of a child diagnosed with permanent neonatal diabetes resulting from a mutation in the KCNJ11 gene encoding the Kir6.2 subunit.

Despite the rarity of permanent neonatal diabetes, this diagnosis should be considered in infants with persistent hyperglycaemia requiring insulin therapy. Children with an ATP-sensitive potassium channel defect in the pancreatic beta cell have an overall good prognosis when treated with oral sulphonylurea therapy.
\end{abstract}

\section{Background}

Diabetes mellitus is a metabolic disease characterized by chronically high glucose levels and can present at any

\section{Corresponding author: \\ Catherine Nyangabyaki-Twesigye, \\ Department of Paediatrics, \\ St. Francis Nsambya Hospital, \\ P. O. Box 7146, Kampala, Uganda, \\ Email: cadyerin@gmail.com \\ Tel: +256772443173}

age from birth ${ }^{1}$. Genetic factors have an important role in the pathogenesis of diabetes and indeed some forms of diabetes mellitus are as a result of a mutation in a single gene $e^{1-5}$.

Monogenic diabetes presenting in infancy may be divided into transient and permanent neonatal diabetes. Both present with hyperglycaemia in infancy however in the former the patient may resolve spontaneously at 3 months with no more insulin requirement until later in life when the disease may relapse. In the latter, insulin supplementation is required for life in the majority of cases. $^{4,6}$

The two commonest forms of neonatal diabetes described are the imprinted anomalies of the 6q24 locus involving the ZAC and HYAMI genes (producing transient neonatal diabetes) and the KCNJ11 gene encoding the Kir6.2 subunit of the ATP sensitive potassium channel (producing permanent neonatal diabetes). Other gene mutations leading to permanent neonatal diabetes include ABCC8 gene mutation involving the SURI subunit of the ATP sensitive potassium channel and INS (insulin) gene mutation.

Making a specific genetic diagnosis is important since it has implications on the type of treatment that should be given, thus improving prognosis. This has particularly been seen with permanent neonatal diabetes secondary to a mutation in the KCNJ11 gene encoding the Kir6.2 subunit where good glycaemic control has been achieved with oral sulphonylureas. ${ }^{7,8}$. 


\section{Case report}

ME was delivered at term by emergency caesarean section following foetal distress. He was a small for gestational age baby with a birth weight of 2,300 grams. He then went through a series of hospital visits and admissions for probable neonatal sepsis.

At 6 weeks of age he presented in DKA (Diabetic ketoacidosis) with a random blood glucose level of $\mathrm{Hi}$ (NR-72-200mg/dl) and $\mathrm{pH}$ of $6.9(\mathrm{NR} ; 7.35-7.45)$ on an arterial blood gas analysis. A septic workup excluded an infectious aetiology.

At discharge, fairly good glycaemic control was achieved with a combination of short acting and intermediate acting insulin. This regimen was maintained for 18 months during which time his average HbA1c was $10.6 \%$. His growth and development progressed normally during this time only complicated by two admissions for recurrence of diabetic ketoacidosis.

Blood samples of the parents and $\mathrm{ME}$ where taken off for genetic testing. Mutation analysis of KCNJ11, ABCC8 and INS genes was undertaken. A missense mutation, p.R201C, on KCNJ11 gene on the Kir6.2 subunit encoding for beta cell ATP-sensitive potassium channel was confirmed with ME. Both his parents were found to be normal. ME was gradually transitioned from insulin to an oral suphonylurea (glibenclamide). His C-peptide assays were $<0.05 \mathrm{ng} / \mathrm{ml}$ (NR-0.8-3.1ng/ $\mathrm{ml}$ ) before initiating glibenclamide tablets and improved to $1.39 \mathrm{ng} / \mathrm{ml}$ two months after the change in treatment. $\mathrm{He}$ is presently 3.5 years with a weight of $16 \mathrm{kgs}$ and height of $122 \mathrm{cms}$. He has an HbA1c of $4.1 \%$. His oral glibenclamide dose was initially at $1.6 \mathrm{mg} / \mathrm{kg} /$ day but has been reduced to $0.9 \mathrm{mg} / \mathrm{kg} /$ day with good glycaemic control, with the tablets being given twice a day.

\section{Discussion}

Monogenic diabetes is an extremely rare condition worldwide, representing $1-2 \%$ of all paediatric diabetes $^{1}$. A database search does not reveal many African cases of neonatal diabetes with one other case reported from Morocco ${ }^{9}$ and a few others from the southern part of Africa. This could be due to the very low index of suspicion, the rarity of the condition and the difficulty in accessing the tests needed to confirm it.

Majority of infants with permanent neonatal diabetes tend to have a low birth weight that is at the $3^{\text {rd }}$ centile or lower ${ }^{3,10,11}$ and many present with associated ketoacidosis. This was the same presentation for ME who was a low birth weight baby and was also diagnosed with diabetes following presentation at 6 weeks of age with ketoacidosis. The low birth weight of most of these babies is due to impaired insulin secretion during the intrauterine period. It is also believed that residual insulin allows the body to continue functioning almost normally for a few weeks after birth before the diagnosis ${ }^{3}$.

A molecular aetiology can be confirmed in most patients by molecular DNA testing,3,7,12. These tests are expensive and not readily accessible in Africa, however some centers outside Africa offer them, at no cost, for research purposes.

The mutation(s) associated with permanent neonatal diabetes mellitus may be dominantly or recessively inherited or may occur as a de novo mutation giving rise to a new case. ${ }^{7} \mathrm{ME}$ had a genetic mutation identified but both his parents had the same genetic testing and were found to be normal, indicating that this was most likely a sporadic mutation. Most of the mutations seen in monogenic diabetes affect the functioning of the insulin producing pancreatic beta cells. ${ }^{1,4,7,10,12}$

The mutation identified was p.R201C on KCNJ11 gene on the Kir6.2 subunit encoding for beta cell ATP-sensitive potassium channel.

This mutation on the KCNJ11 gene causes diabetes by diminishing the responsiveness of the channel to increased ATP and reduced ADP concentrations. This altered sensitivity of the channel to the ATP: ADP ratio results in increased potassium efflux from the cell and cell membrane hyperpolarization results, thus reducing insulin secretion from the beta-cell. ${ }^{4,12}$

Transitioning ME from insulin to sulphonylureas was found to improve his glycaemic control as evidenced by the improvement of his $\mathrm{HbA1}$ c. This is similar to other patients with the same genetic mutation., ${ }^{4,7}$ Although the doses of sulphonylureas required may be higher than those of adults on sulphonlyureas, few side effects have been reported and some patients have been able to reduce the dose with still good glycaemic control. ${ }^{7,8}$ There is good evidence to suggest that diabetes diagnosed in the first 6 months of life is not Type 1 diabetes mellitus since autoantibodies are rarely present ${ }^{7,11}$. The presence of insulin differentiates this condition from Type 1 diabetes where there may be total absence of insulin after the 'honeymoon' period. ${ }^{7}$ Exogenous insulin suppresses the production of insulin in a patient with KCNJ11 gene mutation on insulin therapy. However, when it is discontinued and an oral sulphonylurea is initiated, the body begins to produce insulin and a 
by-product from the metabolism of insulin, C-peptide, is released. This was evident in ME following the change in therapy.

Catch up growth is known to occur in these children once the insulin deficiency is corrected and most of them grow along the same growth centiles as other non-diabetic children with an overall good progno$\operatorname{sis}^{7,8,10}$. The exceptions to this are a certain minority of children with a different type of mutation on the KCNJ11 gene. These patients may have associated neurological disease characterized by developmental delay, muscle weakness, seizures and dysmorphic features ${ }^{6,7}$.

\section{Conclusion}

Neonatal diabetes is known to be a rare condition worldwide but should be suspected in low birth weight infants with persistent hyperglycaemia requiring insulin therapy. A genetic cause can be identified in most of these cases, affecting the choice of treatment.

Most of the children with a KCNJ11 gene mutation affecting the ATP-sensitive potassium channel in the pancreatic beta cell have an overall good prognosis with good glycaemic control attained with oral sulphonylurea therapy.

\section{Acknowledgments}

Our sincere gratitude to Andrew T Hattersley and the University of Exeter Medical school laboratory staff, the ISPAD discussion group and Graham Ogle for their help in managing this child.

\section{References}

1. Edghill EL, Flanagan SE, Patch AM, Boustred C, Parrish A, Shields B, et al. Insulin mutation screening in 1,044 patients with diabetes: mutations in the INS gene are a common cause of neonatal diabetes but a rare cause of diabetes diagnosed in childhood or adulthood. Diabetes. 2008;57(4):1034 PubMed -42:10.2337/ db07-1405

2. Babenko AP, Polak M, Cave H, Busiah K, Czernichow P, Scharfmann R, et al. Activating mutations in the ABCC8 gene in neonatal diabetes mellitus. $N$ Engl J Med. 2006;355(5):456-66:10.1056/NEJMoa055068
3. Gloyn AL, Pearson ER, Antcliff JF, Proks P, Bruining GJ, Slingerland AS, et al. Activating mutations in the gene encoding the ATP-sensitive potassium-channel subunit Kir6.2 and permanent neonatal diabetes. $N$ Engl J Med. 2004;350(18):1838 PubMed -49:10.1056/ NEJMoa032922

4. Sperling MA. ATP-sensitive potassium channels--neonatal diabetes mellitus and beyond. $N$ Engl J Med. 2006;355(5):507 PubMed -10:10.1056/NEJMe068142

5. Stoy J, Edghill EL, Flanagan SE, Ye H, Paz VP, Pluzhnikov A, et al. Insulin gene mutations as a cause of permanent neonatal diabetes. Proceedings of the National Academy of Sciences of the United States of America. 2007;104(38):15040-4:10.1073/pnas.0707291104

6. vonMuhlendahlKE, Herkenhoff H.Long-termcourse of neonatal diabetes. N Engl J Med. 1995;333(11):704 PubMed -8:10.1056/NEJM199509143331105

7. Hattersley A, Bruining J, Shield J, Njolstad $\mathrm{P}$, Donaghue KC. The diagnosis and management of monogenic diabetes in children and adolescents. Pediatric diabetes. 2009;10 Suppl 12:33-42:10.1111/j.1399-5448.2009.00571.x

8. Pearson ER, Flechtner I, Njolstad PR, Malecki MT, Flanagan SE, Larkin B, et al. Switching from insulin to oral sulfonylureas in patients with diabetes due to Kir6.2 mutations. New Engl J Med. 2006;355(5):467 PubMed -77:Doi 10.1056/Nejmoa061759

9. Reis AF, Kannengiesser C, Jennane F, Manna TD, Cheurfa N, Oudin C, et al. Two novel mutations in the EIF2AK3 gene in children with Wolcott-Rallison syndrome. Pediatric diabetes. 2011;12(3 PubMed Pt 1):187-91:10.1111/j.1399-5448.2010.00679.x

10. Al-Matary A, Hussain M, Nahari A, Ali J. Permanent neonatal diabetes mellitus. Am J Case Rep. 2012;13:1435 PubMed :10.12659/AJCR.883242

11. Iafusco D, Stazi MA, Cotichini R, Cotellessa M, Martinucci ME, Mazzella M, et al. Permanent diabetes mellitus in the first year of life. Diabetologia. 2002;45(6):798804:10.1007/s00125-002-0837-2

12. Flanagan SE, Patch AM, Mackay DJ, Edghill EL, Gloyn AL, Robinson D, et al. Mutations in ATP-sensitive $\mathrm{K}+$ channel genes cause transient neonatal diabetes and permanent diabetes in childhood or adulthood. $\mathrm{Di}$ abetes. 2007;56(7):1930-7:10.2337/db07-0043 